\title{
Immunologic adverse reactions of $\beta$-blockers and the skin (Review)
}

\author{
ALIN LAURENTIU TATU ${ }^{1}$, ALINA MIHAELA ELISEI ${ }^{1}$, VALENTIN CHIONCEL ${ }^{2}$, \\ MAGDALENA MIULESCU ${ }^{3}$ and LAWRENCE CHUKWUDI NWABUDIKE ${ }^{4}$
}

\author{
${ }^{1}$ Medical and Pharmaceutical Research Unit/Competitive, Interdisciplinary Research Integrated Platform 'Dunărea de Jos', \\ ReForm-UDJG; Research Centre in the Field of Medical and Pharmaceutical Sciences, Faculty of Medicine and \\ Pharmacy, Department of Pharmaceutical Sciences, 'Dunărea de Jos' University of Galați, 800010 Galati; \\ ${ }^{2}$ Department of Cardio-Thoracic Pathology, Faculty of Medicine, 'Carol Davila' University of \\ Medicine and Phamacy, 050474 Bucharest; ${ }^{3}$ Department of Morphological and Functional Sciences, \\ Faculty of Medicine and Pharmacy, 'Dunarea de Jos University' of Galati, 800010 Galati; ${ }^{4}$ Department of \\ Diabetic Foot Care, 'Prof. N. Paulescu' National Institute of Diabetes, 011233 Bucharest, Romania
}

Received September 11, 2018; Accepted November 16, 2018

DOI: $10.3892 /$ etm.2019.7504

\begin{abstract}
Blockers are a widely utilised class of medication. They have been in use for a variety of systemic disorders including hypertension, heart failure and intention tremors. Their use in dermatology has garnered growing interest with the discovery of their therapeutic effects in the treatment of haemangiomas, their potential positive effects in wound healing, Kaposi sarcoma, melanoma and pyogenic granuloma, and, more recently, pemphigus. Since $\beta$-blockers are deployed in a variety of disorders, which have cutaneous co-morbidities such as psoriasis, their pertinence to dermatologists cannot be overstated. Likewise, $\beta$-blockers, like any other drug category, carry risks of side effects, some of which are dermatologic. These include triggering and exacerbation of psoriasis, psoriatic and rheumatoid arthritis, anaphylaxis, contact dermatitis, occupational contact dermatitis, Raynaud's disease, alopecia, lichen planus-like drug eruption, hyperhydrosis and vitiligo. While recent articles have focussed on the positive uses of $\beta$-blockers, it may also be wise to call our attention to the potential dermatologic adverse effects that may follow $\beta$-blocker
\end{abstract}

Correspondence to: Professor Alin Laurentiu Tatu, Medical and Pharmaceutical Research Unit/Competitive, Interdisciplinary Research Integrated Platform 'Dunărea de Jos', ReForm-UDJG; Research Centre in the Field of Medical and Pharmaceutical Sciences, Faculty of Medicine and Pharmacy, Department of Pharmaceutical Sciences, 'Dunărea de Jos' University of Galați, 39 Al. I. Cuza Street, 800010 Galati, Romania

E-mail: dralin_tatu@yahoo.com

Key words: $\beta$-blockers, drug-induced psoriasis, hyperhydrosis, anaphylaxis, contact dermatitis, lichen planus-like drug eruption, vitiligo, Raynaud's disease, acrocyanosis use, as well as possible therapeutic approaches to these. This short review will focus on those dermatoses resulting from $\beta$-blocker use, which have an immunologic basis.

\section{Contents}

1. Introduction

2. Cutaneous side - effects of $\beta$-blockers

3. Conclusion

\section{Introduction}

$\beta$-Blockers remain one of the most widely used class of therapeutic agents in both cardiac and non-cardiac ailments. Cardiologic diseases for which $\beta$-blockers are presently used include ischemic heart disease, hypertension, arrhythmia and heart failure. Important non-cardiologic applications include glaucoma, migraines, situational anxiety, benign essential tremors and cardiac symptoms of thyrotoxicosis. Not all $\beta$-blockers are equal as they comprise a heterogeneous class of drugs with differing selectivity for $\beta$-adrenoreceptors and extra qualities such as lipophilicity, inverse agonist, intrinsic sympathomimetic and membrane stabilising activities, as well as $\alpha$-receptor blocking properties. The third generation $\beta$-blocker, nebivolol, has additional nitric oxide mediated vasodilating and antioxidant activity (1). Recent data suggest that their metabolic and immunomodulatory effects may extend the scope of their use (2).

$\beta$-Blockers, have garnered interest amongst dermatologists. This growth of interest is based on the discovery of their demonstrated and potential effects in disorders such as vascular malformations (hemangiomas), tumours (Kaposi sarcoma, melanoma), wound healing, pyogenic granulomas and erythemato-telangiectatic rosacea (3).

$\beta$-Blockers are important for dermatology as well, due to their potential adverse reactions. They share the ability 
to produce potentially severe adverse effects, especially in predisposed areas or areas of locus minoris resistentiae in the skin. Consequent upon review, potential alternatives have been proposed (4-10).

We believe this will be a useful complementary article to those works that have highlighted their usefulness (11). A variety of dermatoses may be caused or aggravated by $\beta$-blockers. These include psoriasis, lichen planus-like drug eruptions (LDE), contact dermatitis, anaphylaxis, Raynaud's disease, acrocyanosis, alopecia and hyperhydrosis.

\section{Cutaneous side - effects of $\beta$-blockers}

Keratinocytes possess adrenergic receptors, which have been reported as being exclusively of the $\beta 2$-subtype (12). $\beta 2$-adrenergic receptors are densest at the basal cells and decrease in number towards the stratum corneum, while intracellular calcium concentrations are lowest at the basal cells, increasing towards the stratum corneum thus correlating with keratinocyte differentiation (13).

Psoriasis. Drugs may influence the course of psoriasis in certain ways, including: i) Precipitation of psoriasis de novo in predisposed individuals and in those with a family history; ii) exarcerbation of pre-existing psoriasis lesions; iii) production of psoriatic lesions in clinically normal skin of patients with psoriasis; and iv) development of treatment-resistant psoriasis (11-13).

'Psoriasiform drug disorder' refers to a group of diseases, which mimick psoriasis at some point in their course; these psoriasiform reactions are elicited by inflammatory events leading to dysregulation of cytokines, growth factors and keratinocyte differentiation (14). True drug-induced psoriasis tends to occur in a de novo fashion in patients without a family or prior history and may mimick pustular psoriasis, but without nail or joint involvement (15). Delayed-type hypersensitivity reaction, impaired lymphocyte transformation or alterations in cyclic adenosine monophosphate (cAMP) have been proposed (13-16). cAMP is an intracellular messenger, which brings about the stimulation of proteins for cellular differentiation and inhibition of proliferation (17). Biopsy specimens from $\beta$-blocker-induced (metoprolol and atenolol) eruptions are characterised by excessive degranulation of neutrophils in the dermis. Nonselective $\beta$-blockers (propranolol, nadolol and sotalol) were associated with excessive release of macrophage proteolytic enzymes (18). Metoprolol, nebivolol and bisoprolol are highly selective $\beta 1$-receptor blockers. Nebivolol brought about diminished proinflammatory gene expression in endothelial and vascular smooth muscle cells (19).

Rheumatoid arthritis. Autoimmune disorders may be associated with $\beta 2$-adrenoreceptor dysfunction and examples include: rheumatoid arthritis or systemic lupus erythematosus (20). Modification of $\beta 2$-adrenoreceptor structure could augment sensitivity levels of T-lymphocytes to $\beta 2$-stimulation. This could be a basis for the genetic predisposition to rheumatoid arthritis (21). One study involving murine cells demonstrated a bimodal activity of the sympathetic nervous system. There was proinflammatory activity during the asymptomatic phase and inhibitory activity during the chronic symptomatic phase of arthritis. This supported the idea that $\beta 2$-adrenergic receptor stimulus is time-dependent and may play a role in the treatment of bone destruction in rheumatoid arthritis $(22,23)$.

Thus, $\beta 2$-adrenoreceptor activity is implicated in the generation, progression and treatment of rheumatoid arthritis, and this complex relationship has been mimicked by a variety of other autoimmune diseases, such as psoriasis or psoriatic arthropathy (24). A metoprolol-associated onset of psoriatic arthropathy has been described in a case report (25).

Anaphylaxis. Not surprisingly, as with any other drug, hypersensitivity reactions have occurred to $\beta$-blockers. Epinephrine-resistant anaphylaxis was reported in a patient taking propranolol $40 \mathrm{mg}$ b.d. and intubation was necessary for successful recovery (26). The mechanism of action may in part be due to mast cell priming, which was noted with metoprolol and this augmenting effect was increased when metoprolol was combined with angiotensin coverting enzyme inhibitor (ACE) (27).

Perioccular and occular reactions. Periorbital dermatitis and punctate keratitis, as well as conjunctival and eyelid symptoms were reported in patients on treatment with topical $\beta$-blockers over a 3-month survey period of opthalmologists in The Netherlands (28). Periorbital dermatitis was the most commonly encountered phenomenon and the most commonly encountered culprit was timolol.

One study compared in vitro cytotoxicity, using the MTT assay, of $8 \beta$-blockers (propranolol, alprenolol, atenolol, labetalol, metoprolol, pindolol, timolol and bisoprolol) on cell lines of the human corneal epithelium and retinal pigment epithelium. Primary and immortalised corneal and retinal cell lines were compared for susceptibility to the cytotoxic action of the drugs. $\beta$-Blocker cytotoxicity was also evaluated on human cutaneous keratinocytes and fibroblasts in order to assess susceptibility differences as a function of tissue of origin. Results demonstrated large variations in cytotoxicity ( $\sim 60$-fold) for these closely related drugs from the same cell line (29).

Vitiligo. Patients on systemic $\beta$-blocker therapy could suffer an exacerbation of their vitiligo. Accelerated deterioration of vitiligo lesions was observed in patients treated with $\beta$-blockers (30). Doppler flowmetry and iontophoresis showed increased blood flow in lesions of vitiligo as compared with normal skin, with a more marked increase in segmental vitiligo patients. Segmental vitiligo patients also had an increased density of $\alpha$ - and $\beta$-adrenoceptors (31). This dysfunction of the sympathetic nervous system in the skin of vitiligo patients may provide a basis for the effect of $\beta$-blockers in the pathogenesis of vitiligo and caution should be exercised when vitiligo is part of one of the multiple autoimmune syndrome (vitiligo, lupus and thyroiditis) (32).

Alopecia. Alopecia has been described following topical timolol use in a patient with glaucoma (33). This manifested as tellogen effluvium, which remitted following drug discontinuation and pretreatment hair volume was restored in 14 months. The patient also developed periorbital contact dermatitis after the onset of alopecia. No mechanism was proposed for this 
Table I. Other adverse cutaneous drug reactions of $\beta$-blockers.

\begin{tabular}{ll}
\hline$\beta$-Blocker & Adverse cutaneous drug reactions \\
\hline Atenolol & Vasculitis \\
& Drug-induced lupus erythematosus \\
& Pseudolymphomatous reactions \\
& Lichenoid reactions \\
Acebutolol & Drug-induced lupus erythematosus \\
& Pincer nail deformity \\
& Peyronie's disease \\
Labetalol & Lichenoid reactions \\
& Drug-induced lupus erythematosus \\
& Pincer nail deformity \\
Metoprolol & Peyronie's disease \\
Propranolol & Erythema multiforme \\
& Alopecia \\
& Peyronie's disease \\
& Lichenoid reactions \\
Pindolol & Lichenoid reactions \\
& Drug-induced lupus erythematosus \\
Oxprenolol & Oculocutaneous syndrome \\
& Lichenoid reactions \\
& Drug-induced lupus erythematosus \\
& Vasculitis \\
\hline
\end{tabular}

observation by the authors. Hair growth cycles have, however, been found to be modulated by adrenergic stimulation (34). Nonetheless, the simultaneous onset of contact dermatitis and alopecia, both autoimmune disorders suggests an autoimmune mechanism. Alopecia has long been recognized as an adverse effect of $\beta$-blockers and the suggested mechanism was described by Fraunfelder et al as 'probably a direct toxic effect on the hair follicle'. They also discussed an impressive number of cases and reversibility after stopping the treatment (35-41).

Lichen planus-like drug eruption. Lichenoid drug eruptions may be associated with various $\beta$-adrenergic blocking agents $(42,43)$. Histopathologic analysis has shown increased necrotic keratinocytes grouped in clusters, with increase in plasma cells and eosinophils being more associated with lichen planus-like drug eruption as opposed to lichen planus or other lichenoid disorders (44-47).

The first case in the literature describing lichenoid type cutaneous hyperpigmentation as a form of phototoxicity induced by nebivolol was reported in a 46-year-old female patient. In this case, alternative diagnoses, such as idiopathic lichen planus, systemic connective tissue disease, cutaneous forms of lupus erythematosus, lichenoid contact reaction, and hepatobiliary disease, could be excluded due to the history of the patient, clinical picture, biopsy findings, and time course of the skin lesions. Ultimately, it was concluded that nebivolol may cause lichenoid cutaneous hyperpigmentation. Therefore, in patients using nebivolol, this side effect should be kept in mind (48).
Hyperhydrosis. Hyperhydrosis has been reported in association with $\beta$-adrenoreceptor blockade. Axillary area appears to be the most affected (49). It is not clear whether there is an underlying immune mechanism. Mechanisms based on receptor changes or mediator imbalances (as both cholinergic and adrenergic pathways seem to be involved in sweating) are more likely than autoimmune mechanisms (50). The fact that 'diabetics who become hypoglycemic actually sweat more on propranolol as compared with those who are not on propranolol', may also be relevant in building a working hypothesis (51).

Contact dermatitis. Occupational contact dermatitis was noted in a 48-year old male worker in a pharmaceucitical factory. This affected the patient's hands and the agent was determined to be proproanolol after patch testing (52). The patient improved after he was moved to a different department. Allergic contact dermatitis to $\beta$-adrenergic agents in eye drops has been reported. It is unusual, but timolol was considered by far the greatest culprit (53). The treatment for contact dermatitis to $\beta$-adrenergic agents is topical steroids, which are also known for their own cutaneous adverse reactions (54-57).

$\beta$-Blockers have been successfully used in dermatoses such as hemangiomas, kaposiform haemangioendothelioma, pyogenic granulomas, erythemato-telangiectatic rosacea, angiolymphoid hyperplasia with eosinophillia. There have been promising results in adrenergic urticaria, aquagenic pruritus, wound healing, pemphigus vulgaris, other autoimmune blistering diseases and potentially in melanoma $(58,59)$.

Other immunological and some non-immunological adverse cutaneous drug reactions of $\beta$-blockers are included in Table I: for atenolol-vasculitis (V), drug-induced lupus erythematosus (DILE), pseudolymphomatous reactions (PR); for acebutolol-lichenoid reactions (LR), DILE, pincer nail diformity (PND); for labetalol-Peyronie's disease (PD), LR, DILE; for metoprolol-PND, PD; for propranolol-erythema multiforme, alopecia, PD, LR; for pindolol-LR, DILE; for oxprenolol-oculocutaneous syndrome, LR, DILE; for sotalol-V (60-63).

\section{Conclusion}

This summary review has delved into the immunologic side-effects of $\beta$-blockers. These should be borne in mind by dermatologists, cardiologists, opthalmologists, neurologists, pediatricians, internists, family physicians and other specialists that prescribe this category of drugs.

With regard to medical ethics, it may be useful, prior to the prescription and administration of $\beta$-blockers to inform our patients of the possible adverse reactions and making them sign an informed consent form $(64,65)$. In the future, in order to obviate such potential risks perhaps plant extracts with limited potential for adverse reactions and benign alternative treatments could be investigated and utilised $(66,67)$, especially as knowledge removes discomfort $(68,69)$.

\section{Acknowledgements}

Not applicable. 


\section{Funding}

No funding was received.

\section{Availability of data and materials}

Not applicable.

\section{Authors' contributions}

ALT, VC, MM contributed to the conception, design, and drafting the study. AME and LCN contributed to the interpretation of the data, and revising the manuscript critically for important intellectual content. All authors read and approved the final manuscript and contributed equally in all the stages of the study. They reached an agreement to be accountable for all aspects of the work in ensuring that questions related to the accuracy or integrity of any part of the work are appropriately investigated and resolved.

\section{Ethics approval and consent to participate}

Not applicable.

\section{Patient consent for publication}

Not applicable.

\section{Competing interests}

The authors declare that they have no competing interests.

\section{References}

1. Akbar S and Alorainy MS: The current status of $\beta$-blockers' use in the management of hypertension. Saudi Med J 35: 1307-1317, 2014.

2. Pemberton $P$, Veenith T, Snelson $\mathrm{C}$ and Whitehouse T: Is it time to beta block the septic patient? Biomed Res Int 2015: 424308, 2015.

3. Loftus TJ, Efron PA, Moldawer LL and Mohr AM: $\beta$-blockade use for traumatic injuries and immunomodulation: A review of proposed mechanisms and clinical evidence. Shock 46: 341-351, 2016.

4. Nwabudike LC and Tatu AL: Response to chronic exposure to tetracyclines and subsequent diagnosis for non-melanoma skin cancer in a large Mid-Western US population. J Eur Acad Dermatol Venereol 32: e159, 2018.

5. Tatu AL and Nwabudike LC: Bullous reactions associated with COX-2 inhibitors. Am J Ther 24: e477-e480, 2017.

6. Gheorghe I, Tatu AL, Lupu I, Thamer O, Cotar AI, Pircalabioru GG, Popa M, Cristea VC, Lazar V and Chifiriuc MC: Molecular characterization of virulence and resistance features in Staphylococcus aureus clinical strains isolated from cutaneous lesions in patients with drug adverse reactions. Rom Biotechnol Lett 22: 12321-12327, 2017.

7. Happle R and Kluger N: Koebner's sheep in Wolf's clothing: does the isotopic response exists as a distinct phenomenon? J Eur Acad Dermatol Venereol 32: 542-543, 2018.

8. Gambichler T, Rüddel I, Hessam S, Bechara FG, Stockfleth E and Schmitz L: Altered epigenetic pathways and cell cycle dysregulation in healthy appearing skin of patients with koebnerized squamous cell carcinomas following skin surgery. J Eur Acad Dermatol Venereol 32: 1485-1491, 2018.

9. Tantu M, Belu E, Bobescu E, Armean SM, Armean P, Constantin MM and Domnariu CD: Role of angiotensin converting enzyme (ACE) inhibitors in hypertension and cardiovascular protection management. Farmacia 62: 443-451, 2014.
10. Chen $L$ and Tsai TF: The role of $\beta$-blockers in dermatological treatment: A review. J Eur Acad Dermatol Venereol 32: 363-371, 2018.

11. Sivamani RK, Lam ST and Isseroff RR: Beta adrenergic receptors in keratinocytes. Dermatol Clin 25: 643-653, 2007.

12. Yilmaz MB, Turhan H, Akin Y, Kisacik HL and Korkmaz S: Beta-blocker-induced psoriasis: A rare side effect - a case report. Angiology 53: 737-739, 2002.

13. O'Brien $\mathrm{M}$ and Koo J: The mechanism of lithium and betablocking agents in inducing and exacerbating psoriasis. J Drugs Dermatol 5: 426-432, 2006.

14. Tsankov N, Angelova I and Kazandjieva J: Drug-induced psoriasis. Recognition and management. Am J Clin Dermatol 1: 159-165, 2000.

15. Sehgal VN, Dogra S, Srivastava G and Aggarwal AK: Psoriasiform dermatoses. Indian J Dermatol Venereol Leprol 74: 94-99, 2008.

16. Fry L and Baker BS: Triggering psoriasis: The role of infections and medications. Clin Dermatol 25: 606-615, 2007.

17. Halevy S and Livni E: Psoriasis and psoriasiform eruptions associated with propranolol - the role of an immunological mechanism. Arch Dermatol Res 283: 472-473, 1991.

18. Kim GK and Del Rosso JQ: Drug-provoked psoriasis: is it drug induced or drug aggravated?: understanding pathophysiology and clinical relevance. J Clin Aesthet Dermatol 3: 32-38, 2010.

19. Shaw SM, Coppinger T, Waywell C, Dunne L, Archer LD, Critchley WR, Yonan N, Fildes JE and Williams SG: The effect of beta-blockers on the adaptive immune system in chronic heart failure. Cardiovasc Ther 27: 181-186, 2009.

20. Wahle M, Krause A, Pierer M, Hantzschel H and Baerwald CG: Immunopathogenesis of rheumatic diseases in the context of neuroendocrine interactions. Ann NY Acad Sci 966: 355-364, 2002.

21. Eyre S, Bowes J, Potter C, Worthington J and Barton A: Association of the FCRL3 gene with rheumatoid arthritis: A further example of population specificity? Arthritis Res Ther 8: R117, 2006.

22. Lubahn CL, Schaller JA, Bellinger DL, Sweeney S and Lorton D: The importance of timing of adrenergic drug delivery in relation to the induction and onset of adjuvant-induced arthritis. Brain Behav Immun 18: 563-571, 2004.

23. Härle P, Möbius D, Carr DJ, Schölmerich J and Straub RH: An opposing time-dependent immune-modulating effect of the sympathetic nervous system conferred by altering the cytokine profile in the local lymph nodes and spleen of mice with type II collagen-induced arthritis. Arthritis Rheum 52: 1305-1313, 2005.

24 . Fan X and Wang I: $\beta 2$ Adrenergic receptor on T lymphocytes and its clinical implications. Prog Nat Sci 19: 17-23, 2009.

25. Tatu AL and Nwabudike LC: Metoprolol-associated onset of psoriatic arthropathy. Am J Ther 24: e370-e371, 2017.

26. Newman BR and Schultz LK: Epinephrine-resistant anaphylaxis in a patient taking propranolol hydrochloride. Ann Allergy 47: 35-37, 1981

27. Nassiri M, Babina M, Dölle S, Edenharter G, Ruëff F and Worm M: Ramipril and metoprolol intake aggravate human and murine anaphylaxis: Evidence for direct mast cell priming. J Allergy Clin Immunol 135: 491-499, 2015.

28. van Beek LM, de Keizer RJ, Polak BCP, Elzenaar PR, van Haeringen NJ and Kijlstra A: Incidence of ocular side effects of topical $\beta$ blockers in the Netherlands. Br J Ophthalmol 84: 856-859, 2000.

29. Cheong HI, Johnson J, Cormier M and Hosseini K: In vitro cytotoxicity of eight $\beta$-blockers in human corneal epithelial and retinal pigment epithelial cell lines: Comparison with epidermal keratinocytes and dermal fibroblasts. Toxicol In Vitro 22: 1070-1076, 2008.

30. Schallreuter KU: Beta-adrenergic blocking drugs may exacerbate vitiligo. Br J Dermatol 132: 168-169, 1995.

31. Wu CS, Yu HS, Chang HR, Yu CL, Yu CL and Wu BN: Cutaneous blood flow and adrenoceptor response increase in segmental-type vitiligo lesions. J Dermatol Sci 23: 53-62, 2000.

32. Tatu AL and Ionescu MA: Multiple autoimmune syndrome type III-thyroiditis, vitiligo and alopecia areata. Acta Endo Buc 13: 124-125, 2017.

33. Muramatsu K, Nomura T, Shiiya C, Nishiura K and Tsukinaga I: Alopecia induced by timolol eye-drops. Acta Derm Venereol 97: 295-296, 2017.

34. Botchkarev VA, Peters EM, Botchkareva NV, Maurer M and Paus R: Hair cycle-dependent changes in adrenergic skin innervation, and hair growth modulation by adrenergic drugs. J Invest Dermatol 113: 878-887, 1999. 
35. Lewis RV and Lofthouse C: Adverse reactions with beta-adrenoceptor blocking drugs. An update. Drug Saf 9: 272-279, 1993.

36. Fraunfelder FT, Meyer SM and Menacker SJ: Alopecia possibly secondary to topical ophthalmic $\beta$-blockers. JAMA 263: 1493-1494, 1990.

37. Richards S: Cutaneous side-effects of beta-adrenergic blockers. Australas J Dermatol 26: 25-28, 1985.

38. Shelley ED and Shelley WB: Alopecia and drug eruption of the scalp associated with a new beta-blocker, nadolol. Cutis 35 : 148-149, 1985.

39. England JR and England JD: Alopecia and propranolol therapy. Aust Fam Physician 11: 225-226, 1982.

40. Hilder RJ: Propranolol and alopecia. Cutis 24: 63-64, 1979.

41. Martin CM, Southwick EG and Maibach HI: Propranolol induced alopecia. Am Heart J 86: 236-237, 1973.

42. Bodmer M, Egger SS, Hohenstein E, Beltraminelli $\mathrm{H}$ and Krähenbühl S: Lichenoid eruption associated with the use of nebivolol. Ann Pharmacother 40: 1688-1690, 2006.

43. Meyer S, Burgdorff T, Szeimies RM, Vogt T, Landthaler M and Karrer S: Management of erosive lichen planus with topical tacrolimus and recurrence secondary to metoprolol. J Eur Acad Dermatol Venereol 19: 236-239, 2005

44. Brănisteanu DE, Pintilie A and Dimitriu A, Cerbu A, Ciobanu D, Oanţă A and Tatu AL: Clinical, laboratory and therapeutic profile of lichen planus. Rev Med Chir Soc Med Nat Iasi 121: 25-32, 2017 (In Romanian).

45. Lage D, Juliano PB, Metze K, de Souza EM and Cintra ML: Lichen planus and lichenoid drug-induced eruption: A histological and immunohistochemical study. Int J Dermatol 51: $1199-1205,2012$

46. Brănişteanu DE, Brănişteanu DC, Stoleriu G, Ferariu D, Voicu CM, Stoica LE, Căruntu C, Boda D, Filip-Ciubotaru FM, Dimitriu A, et al: Histopathological and clinical traps in lichen sclerosus: A case report. Rom J Morphol Embryol 57 (Suppl 2): 817-823, 2016

47. Tatu AL and Nwabudike LC: The treatment options of male genital lichen sclerosus et atrophicus: Treatments of Genital Lichen Sclerosus Conference: 14th National Congress of Urogynecology (Urogyn) Location: Eforie, Romania Date: Sep 07-09, 2017. Proceedings of the 14th National Congress of Urogynecology and the National Conference of the Romanian Association for the Study of Pain, pp262-264, 2017.

48. Aslan AN, Güney MC, Akçay M, Keles T and Bozkurt E: Lichenoid type cutaneous hyperpigmentation induced by nebivolol. Turk Kardiyol Dern Ars 45: 268-270, 2017.

49. Schmutz JL, Houet C, Trechot P, Barbaud A and Gillet-Terver MN Sweating and beta-adrenoceptor antagonists. Dermatology 190: 86, 1995.

50. Shields SA, MacDowell KA, Fairchild SB and Campbell ML: Is mediation of sweating cholinergic, adrenergic, or both? A comment on the literature. Psychophysiology 24: 312-319, 1987.

51. Lama PJ: Systemic adverse effects of beta-adrenergic blockers: An evidence-based assessment. Am J Ophthalmol 134: 749-760, 2002.

52. Ali FR, Shackleton DB, Kingston TP and Williams JD: Occupational exposure to propranolol: A rarely recognised cause of allergic contact dermatitis. Int J Occup Med Environ Health 28: 639-640, 2015

53. Jappe U, Uter W, Menezes de Pádua CA, Herbst RA and Schnuch A: Allergic contact dermatitis due to beta-blockers in eye drops: A retrospective analysis of multicentre surveillance data 1993-2004. Acta Derm Venereol 86: 509-514, 2006.
54. Tatu AL: Topical steroid induced facial rosaceiform dermatitis. Acta Endo (Buc) 12: 232-233, 2016.

55. Tatu AL, Ionescu MA, Clatici VG and Cristea VC: Bacillus cereus strain isolated from Demodex folliculorum in patients with topical steroid-induced rosaceiform facial dermatitis. An Bras Dermatol 91: 676-678, 2016.

56. Tatu AL, Ionescu MA and Nwabudike LC: Contact allergy to topical mometasone furoate confirmed by rechallenge and patch test. Am J Ther 25: e497-e498, 2018.

57. Tatu AL and Clătici V: Some correlations between the clinical and dermoscopic features of steroid induced facial dermatitis. J Am Acad Dermatol 72: 91, 2015.

58. Miyamoto D, Maruta CW, Santi CG, Zoroquiain P, Dias AB, Mansure JJ, Burnier MN Jr and Aoki V: Exploring the in situ expression of vascular endothelial growth factor and endoglin in pemphigus foliaceus variants and pemphigus vulgaris. J Eur Acad Dermatol Venereol: Feb 28, 2018 (Epub ahead of print). doi: $10.1111 / j d v .14903$

59. Abdelmaksoud A and Vestita M: Beta-blockers for treatment of autoimmune blistering dermatosis. JEur Acad Dermatol Venereol: May 6, 2018 (Epub ahead of print). doi: 10.1111/jdv.15054.

60. Prabha N, Chhabra N and Arora R: Beta-blockers in dermatology. Indian J Dermatol Venereol Leprol 83: 399-407, 2017.

61. Manu P and Rogozea LM: Propranolol for angina pectoris. Am J Ther 23: e1285-e1286, 2016.

62. Bilewicz-Stebel M, Miziołek B, Bergler-Czop B and Stańkowska A: Drug-induced subacute cutaneous lupus erythematosus caused by a topical beta blocker - timolol. Acta Dermatovenerol Croat 26: 44-47, 2018.

63. Pulitzer MP, Nolan KA, Oshman RG and Phelps RG: CD $30^{+}$ lymphomatoid drug reactions. Am J Dermatopathol 35: 343-350, 2013.

64. Rogozea LM, Diaconescu DE, Dinu EA, Badea O, Popa D, Andreescu O and Leaşu FG: Bioethical dilemmas in using animal in medical research. Challenges and opportunities. Rom J Morphol Embryol 56: 1227-1231, 2015.

65. Purcaru D, Preda A,Popa D, Moga MA and Rogozea L: Informed consent: How much awareness is there? PLoS One 9: e110139, 2014.

66. Dumitriu BO, Fasie V, Mardare N, Diaconu C and Gurau G and Tatu AL: Formulation, preparation, physico-chimical analysis, microbiological peculiarities and therapeutic challenges of extractive solution of Kombucha. Rev Chim (Bucharest) 69: 720-724, 2018

67. Robu S, Chesaru BI, Diaconu C, Dumitriu BO, Tutunaru D, Stanescu U and Lisa EL: Lavandula hybrida: Microscopic characterization and the evaluation of the essential oil. Farmacia 64: 914-917, 2016.

68. Nwabudike LC: Case reports of acne and homeopathy. Complement Med Res 25: 52-55, 2018.

69. Nwabudike LC: Knowledge removes discomfort. JAMA Dermatol 154: 738-739, 2018.

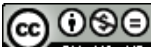

This work is licensed under a Creative Commons Attribution-NonCommercial-NoDerivatives 4.0 International (CC BY-NC-ND 4.0) License. 